\title{
Factors associated with duration of breastfeeding in Spain: a cohort study
}

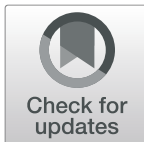

\author{
Carolina Lechosa-Muñiz ${ }^{1 \dagger}$, María Paz-Zulueta ${ }^{2^{*}} \mathbb{D}$, Sonia Mateo Sota ${ }^{1}$, María Sáez de Adana Herrero ${ }^{1}$ \\ Elsa Cornejo del Rio ${ }^{1}$, Javier Llorca ${ }^{3,4+}$ and María J. Cabero-Perez ${ }^{1,3+}$
}

\begin{abstract}
Background: Factors associated with duration of breastfeeding have been usually studied at specific times after birth. Little is known about how much time is added to breastfeeding by each associated factor.

Methods: A cohort of 969 mother-child dyads was followed-up for twelve months at the Marqués de Valdecilla University Hospital, Spain, in 2018. Data on mother characteristics, pregnancy, delivery and children characteristics were obtained from medical records. Length of breastfeeding was reported by the mothers and recorded in paediatric medical record at hospital discharge and 2, 4, 6, 9 and 12 months of life. Factors associated with duration of breastfeeding were analysed via multivariate Weibull regression parameterized as accelerated time of failure. Results are presented as time ratios.

Results: About four out of five children were breastfed at hospital discharge, although this proportion dropped to $65 \%$ in children born from smoker women, $70 \%$ in preterm children and $68 \%$ in neonates weighting less than $2500 \mathrm{~g}$. Mother's age was associated with longer breastfeeding, adding $2 \%$ more breastfeeding time per year (adjusted time ratio 1.02; 95\% confidence interval 1.00, 1.04). Children born from mothers with university studies were breastfed 53\% more time than those born from mothers with primary studies (adjusted time ratio 1.53; 95\% confidence interval 1.21, 1.95); smoking in pregnancy decreased length of breastfeeding by $41 \%$ (adjusted time ratio $0.59 ; 95 \%$ confidence interval $0.46,0.76$ ). Other factors associated with longer breastfeeding were single pregnancy and newborn weight over $2500 \mathrm{~g}$.
\end{abstract}

Conclusions: Analysing factors associated with duration of breastfeeding as time parameters allows us to quantify the amount of time gained or lost by each factor, which could make it easier to evaluate the relevance of programmes directed to promote facilitating breastfeeding factors.

Keywords: Breastfeeding, Smoking in pregnancy, Educational level, Maternal age

\section{Background}

The World Health Organization recommends that "infants should be exclusively breastfeeding for the first six months of life" with further breastfeed supplemented with solid meals until 24 months or more, or for as long

\footnotetext{
*Correspondence: maria.paz@unican.es

${ }^{\dagger}$ Carolina Lechosa-Muñiz and María Paz-Zulueta Shared first authorshipJavier Llorca and María J Cabero-Perez Shared senior authorship

${ }^{2}$ Faculty of Nursing, Universidad de Cantabria. IDIVAL, Gl Derecho Sanitario y Bioética. GRIDES, 39008 Santander, Spain

Full list of author information is available at the end of the article
}

as the mother and baby desire [1], and scientific societies in America and Europe adhere this position [2, 3]. Breastfeeding rates reached $56-98 \%$ immediately after birth in European countries [4], however, it drops to 38$71 \%$ at 6 months after birth and only 13-39\% if only exclusively breastfeeding is considered [4].

Factors favouring breastfeeding both onset and continuation, include higher maternal education $[5,6]$, parity $[6,7]$, birth at term [5], vaginal delivery $[8,9]$, maternal smoking $[8,10,11]$ and skin-to-skin mother-

(c) The Author(s). 2020 Open Access This article is licensed under a Creative Commons Attribution 4.0 International License, which permits use, sharing, adaptation, distribution and reproduction in any medium or format, as long as you give appropriate credit to the original author(s) and the source, provide a link to the Creative Commons licence, and indicate if changes were made. The images or other third party material in this article are included in the article's Creative Commons licence, unless indicated otherwise in a credit line to the material. If material is not included in the article's Creative Commons licence and your intended use is not permitted by statutory regulation or exceeds the permitted use, you will need to obtain permission directly from the copyright holder. To view a copy of this licence, visit http://creativecommons.org/licenses/by/4.0/ The Creative Commons Public Domain Dedication waiver (http://creativecommons.org/publicdomain/zero/1.0/) applies to the data made available in this article, unless otherwise stated in a credit line to the data. 
infant contact shortly after birth [12]. A recent metaanalysis confirmed these results, finding that the influence of these factors on breastfeeding continuation was similar to that of the initiation of breastfeeding and confirmed the importance of previous experience, nonseparation of dyads, and education in breastfeeding [13]. The fact that such an influence was measured via relative risk at specific times (e.g. 3 months after birth) put a limitation to its interpretability. For instance, let us consider four women abandoning breastfeeding at 1 week, 2 months +3 weeks, 3 months +1 week and 6 months of life, respectively. In such analysis, the first two would have been classified as failure because they were not breastfeeding at 3 months and the other two as success as they were both breastfeeding at 3 months. The second and the third women, however, have much in common with each other regarding the length of breastfeeding than with the others. Instead, we have studied factors associated with breastfeeding continuation using survival techniques. The aim of our study was to estimate not only which factors are related to prolonged breastfeeding, but also the amount of breastfeeding time gained by each factor.

\section{Methods}

\section{Design and setting}

We carried out a prospective cohort study by recruiting 969 consecutive newborns in the University Hospital Marqués de Valdecilla (HUMV), Santander, Spain, from 1st January 2018 to 31st August 2018. The HUMV attends about 3000 deliveries per year and is immersed in the Baby-Friendly Hospital Initiative. Women who rejected to sign the informed consent and those who did live in the region were excluded from the study. Details on recruitment and gathering information have been published elsewhere [11].

\section{Data collection}

Data obtained from maternal medical records included maternal age, parity, educational level, occupational activity, pregnancy duration and type of delivery. Information on smoking in pregnancy was obtained by interview when the mother was admitted for delivery; no information on smoking was obtained in the follow-up. From newborn medical records we gathered her/his gender, weight at birth and whether she/he was singleton or twin. Newborn attendance to child care was obtained by interviewing the mother in each check-up at 2, 4, 6, 9 and 12 months of life.

Type of feeding was obtained at hospital discharge and from the paediatric record of the health checks established in the regional Health Service's child care program at 2, 4, 6, 9 and 12 months of life. All participants were followed-up for 1 year in order to ascertain the breastfeeding duration.

\section{Data measures}

Educational level was classified as primary studies, secondary studies, short cycle in higher education e.g.: Foundation Degree or similar- and university studies. Occupational activity was classified as working, unemployed, inactive and student. Pregnancy duration was recorded in weeks and days and later categorized as < 34 weeks, 34-36 weeks, $\geq 37$ weeks. Type of delivery was grouped in vaginal (non-instrumental), cesarean rate or instrumental. Weight at birth was sorted as low weight $(<2500 \mathrm{~g})$, normal (2500-4000 g) and overweight (> $4000 \mathrm{~g})$.

Type of feeding (exclusive maternal milk, mixed -maternal plus other options, and infant formula milk, defined as in [1]) was obtained at hospital discharge. In this regard, exclusive breastfeeding at discharge is considered for infants who have been exclusively breastfed or who have received expressed breast milk from birth to discharge. In the other time points studied the statistics are obtained with the food received in the last $24 \mathrm{~h}$ Thus, exclusively breastfed children are those who have received only breast milk, mixed- children who have received some formula supplement, and infant formula fed. Type of feeding was also obtained from the paediatric record of the health checks established in the regional Health Service's child care program at 2, 4, 6, 9 and 12 months of life. All participants were followed-up for 1 year in order to ascertain the breastfeeding duration.

\section{Statistical analysis}

The minimum required sample size was $n=805$. This figure was obtained in order to estimate the proportion of breastfeeding with $5 \%$ precision, assuming the worst case scenario (i.e. proportion $=50 \%$ ) and alpha error $=$ 0.05 . Descriptive results are presented as number (percentage) or mean \pm standard deviation. Means were compared using ANOVA and percentages via chisquared test. The analysis was carried out using the time variable was length of breastfeeding and participants interrupting breastfeeding were considered events. Estimates were obtained using the Kaplan-Meier method. The relationships between woman and newborn characteristics and length of breastfeeding were analysed via Weibull regression parameterized as accelerated time of failure [14]. Of note, Weibull regression could be parameterized in two ways, proportional hazards or accelerated time of failure. The most frequent parameterization is proportional hazards, then, the main result is usually expressed as hazard ratio. Accelerated time of failure parameterization, however, displays its main result as 
time ratio, as time is a more natural and immediately understandable unit than hazard, time ratios are easier to interpret. For instance, time ratio $=2$ would mean length of breastfeeding doubled that of the reference category and time ratio $=0.5$ would mean length of breastfeeding halved that of the reference category. After the Weibull analysis took place, we estimated adjusted medians and means of breastfeeding duration according to different mother or child characteristics.

\section{Results}

The initial sample was 992 infants included in the study at birth. A child was excluded because she died at 2 months of age, she was born in the 25th week of gestation, weighting $870 \mathrm{~g}$, she was immediately admitted in the pediatric ICU and had never the opportunity of being breastfed. Twenty-two children were excluded because their parents were not residing in the region. Finally, 969 newborns from 949 pregnancies were included in the analysis, and 882 children (91\%) were followed-up until 12 months. A flowchart with the recruitment and follow-up data appears in Fig. 1.

Mothers were $33.7 \pm 5.2$ years on average; more than one in three had attended university studies $(n=350$, $36.9 \%$ ) and about $70 \%$ were active workers. One in eight women declared to have smoked in pregnancy.

Only 59 (6.1\%) newborns were preterm and 40 (4.1\%) were twins.

More than 90\% newborns weighted between 2500 and $4000 \mathrm{~g}$ at birth, $83(8.6 \%)$ weighted less than $2500 \mathrm{~g}$ and 78 (8.1\%) weighted more than $4000 \mathrm{~g}$. More than 50\% newborns were breastfed at hospital discharge (Table 1).

About $79 \%$ children were breastfed at hospital children, and the percentage dropped to 57, 43 and $32 \%$ at 3, 6 and 9 months after birth, respectively (Table 2 and Fig. 2). Children born from smoker women were less likely breastfed than those born from non-smoker women ( $65 \%$ vs. $81 \%$ at hospital discharge and $23 \%$ vs. $46 \%$ at 6 months) (Table 2 and Fig. 3a); these differences still hold when analysing only children with exclusive maternal milk at hospital discharge (Fig. 3b). About 80\% children born at term were breastfed, contrasting with less than $70 \%$ of preterm children, and those with gestation shorter than 34 weeks had a faster decline in breastfeeding (Table 2). Newborn weight lower than $2500 \mathrm{~g}$ was associated with lower percentages of breastfeeding than newborn weight between 2500 and $4000 \mathrm{~g}$, 68\% vs $80 \%$ at hospital discharge and $31 \%$ vs $44 \%$ at 6 months (Table 2 and Fig. 3c). Children born from women with university studies were more likely to be breastfed than those born from women with lower educational level (Table 2 and Fig. 3d).

Table 3 displays results from Weibull regression. Each additional year in maternal age increased breastfeeding

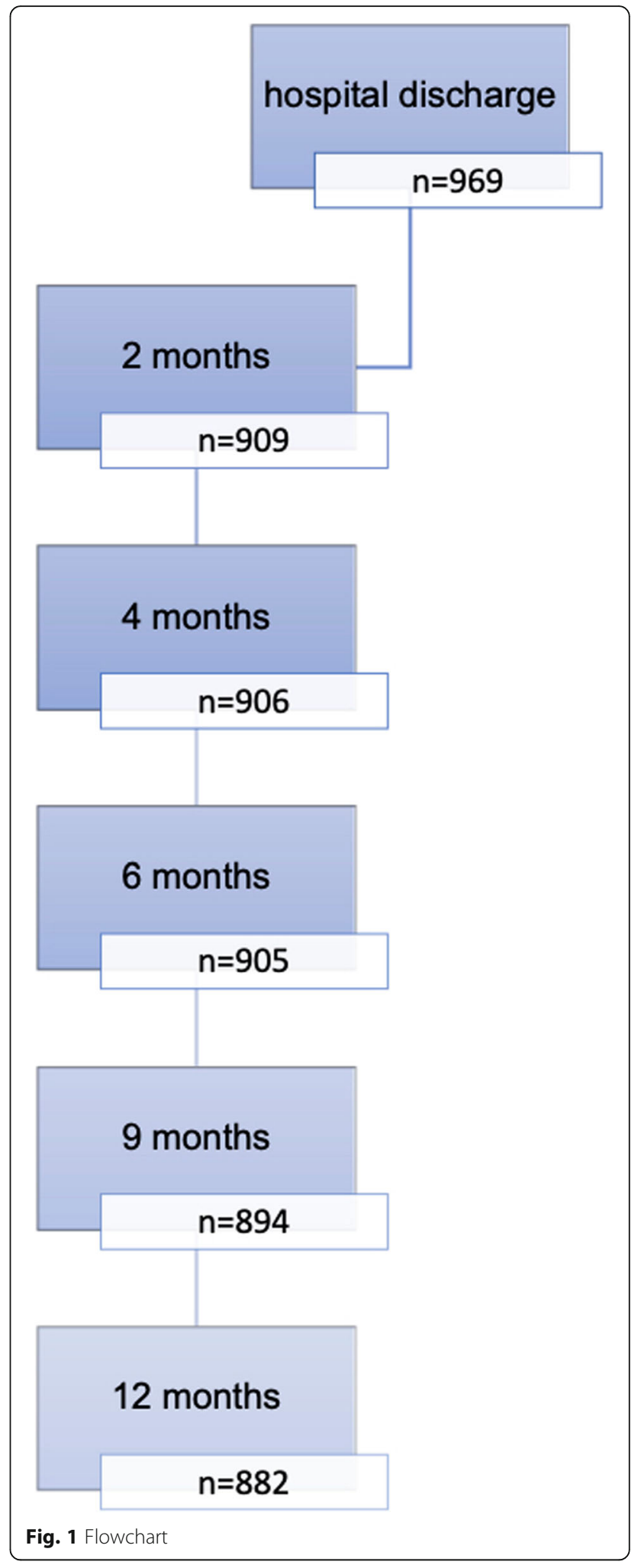

time by $2 \%$ in the multivariate analysis (adjusted time ratio 1.02; 95\% confidence interval (CI) 1.00, 1.04). Women with university studies breastfed for $53 \%$ more time than women with primary studies (adjusted time 
Table 1 Main characteristics of participants in the study

\begin{tabular}{|c|c|c|c|c|c|}
\hline Variable & Category & $\begin{array}{l}\text { All } \\
\text { participants } \\
(N=969)\end{array}$ & $\begin{array}{l}\text { Participants with exclusive } \\
\text { breastfeeding at hospital discharge } \\
(N=520)\end{array}$ & $\begin{array}{l}\text { Participants without exclusive } \\
\text { breastfeeding at hospital discharge } \\
(N=449)\end{array}$ & $p$ value \\
\hline Maternal age & Mean \pm sd & $33.7 \pm 5.2$ & $33.7 \pm 5.0$ & $33.6 \pm 3.9$ & $0.76^{*}$ \\
\hline \multirow{4}{*}{$\begin{array}{l}\text { Maternal } \\
\text { educational } \\
\text { level }\end{array}$} & Primary studies & $215(22.7)$ & $91(17.6)$ & $124(27.6)$ & $<0.001^{* *}$ \\
\hline & $\begin{array}{l}\text { Secondary } \\
\text { studies }\end{array}$ & $112(11.8)$ & $60(11.6)$ & $53(11.8)$ & \\
\hline & $\begin{array}{l}\text { Foundation } \\
\text { degree }\end{array}$ & $272(28.7)$ & $147(28.4)$ & $134(29.8)$ & \\
\hline & $\begin{array}{l}\text { University } \\
\text { studies }\end{array}$ & $350(36.9)$ & $220(42.5)$ & $138(30.7)$ & \\
\hline \multirow{4}{*}{$\begin{array}{l}\text { Maternal } \\
\text { occupation }\end{array}$} & Working & $660(69.6)$ & $368(71.0)$ & $303(67.5)$ & $0.64^{* *}$ \\
\hline & Unemployed & $163(17.2)$ & $84(16.2)$ & 85 (18.9) & \\
\hline & Inactive & $116(12.2)$ & $61(11.8)$ & $56(12.5)$ & \\
\hline & Student & $10(1.1)$ & $5(1.0)$ & $5(1.1)$ & \\
\hline \multirow{2}{*}{$\begin{array}{l}\text { Smoking in } \\
\text { pregnancy }\end{array}$} & No & $830(87.5)$ & $467(90.2)$ & $378(84.2)$ & $0.005^{* *}$ \\
\hline & Yes & $119(12.5)$ & $51(9.8)$ & 71 (15.8) & \\
\hline \multirow{3}{*}{$\begin{array}{l}\text { Pregnancy } \\
\text { duration }\end{array}$} & $\geq 37$ weeks & 897 (94.5) & $501(96.7)$ & $408(90.9)$ & $0.001^{* *}$ \\
\hline & 34-36 weeks & $36(3.8)$ & $11(2.1)$ & $28(6.2)$ & \\
\hline & $<34$ weeks & $16(1.7)$ & $6(1.2)$ & $13(2.9)$ & \\
\hline \multirow[t]{3}{*}{ Type of delivery } & $\begin{array}{l}\text { Vaginal (non- } \\
\text { instrumental) }\end{array}$ & $653(67.4)$ & $391(75.2)$ & $262(58.4)$ & $<0.001^{* *}$ \\
\hline & Instrumental & $80(8.3)$ & $43(8.3)$ & 37 (12.9) & \\
\hline & Cesarean rate & $236(24.4)$ & $86(16.5)$ & $150(33.4)$ & \\
\hline \multirow{2}{*}{$\begin{array}{l}\text { Newborn } \\
\text { gender }\end{array}$} & Male & $490(50.6)$ & $255(49.0)$ & $235(52.3)$ & $0.31^{* *}$ \\
\hline & Female & $479(49.4)$ & $265(51.0)$ & $214(47.7)$ & \\
\hline \multirow[t]{2}{*}{ Twin pregnancy } & No & $929(95.9)$ & $516(99.2)$ & $413(92.0)$ & $<0.001^{* *}$ \\
\hline & Yes & $40(4.1)$ & $4(0.8)$ & $36(8.0)$ & \\
\hline \multirow{3}{*}{$\begin{array}{l}\text { Newborn } \\
\text { weight }\end{array}$} & $<2500$ & $83(8.6)$ & $23(4.4)$ & $60(13.4)$ & $<0.001^{* *}$ \\
\hline & 2500-4000 g & 808 (93.4) & $463(89.0)$ & 345 (76.8) & \\
\hline & $>4000 \mathrm{~g}$ & $78(8.1)$ & $34(6.5)$ & $44(9.8)$ & \\
\hline \multirow{2}{*}{$\begin{array}{l}\text { Breastfeeding } \\
\text { duration }\end{array}$} & Mean $\pm s d$ & $5.9 \pm 5.2$ & $7.8 \pm 4.6$ & $3.9 \pm 4.9$ & $<0.001^{*}$ \\
\hline & Yes & $520(53.7)$ & $520(100.0)$ & - & \\
\hline \multirow{3}{*}{$\begin{array}{l}\text { Attendance to } \\
\text { child care }\end{array}$} & No & 763 (78.7) & $398(76.5)$ & 365 (81.3) & $0.09^{* *}$ \\
\hline & Yes & $132(13.6)$ & $74(14.2)$ & 58 (12.9) & \\
\hline & Unknown & $74(7.6)$ & $48(9.2)$ & $26(5.8)$ & \\
\hline
\end{tabular}

*ANOVA. ${ }^{* *}$ Chi-squared test

ratio 1.53 ; 95\% CI 1.21, 1.95). Women who smoked in pregnancy almost halved the time of breastfeeding (adjusted time ratio $0.59 ; 95 \%$ CI $0.46,0.76$ ) as also did twin pregnancy (adjusted time ratio 0.57; 95\% CI 0.37, 0.89). Newborns weighting less than 2500 g were breastfed less time than newborns with normal weight, although this result was not statistically significant in the multivariate analysis (adjusted time ratio 0.77; 95\% CI 0.53, 1.11).

In order to better explain the relevance of multivariate results in Table 3, let us suppose we want to compare two groups of mothers: group A are mothers 35 years old, with university studies and smokers and group B are mothers 30 years old, with primary studies and no smokers. Then, using results from the multivariate model in Table 3, time ratio (TR) comparing group A with group $\mathrm{B}$ can be estimated as:

$$
\begin{aligned}
T R & =T R_{\text {age }}^{35-30} \times T R_{\text {university }} \times T R_{\text {smoking }} \\
& =1.02^{5} \times 1.53 \times 0.59=1.00,
\end{aligned}
$$

showing that the deleterious effect of smoking in pregnancy cancels out the combined positive effects of five additional years and university studies on breastfeeding duration. 
Table 2 Percentage of newborns breastfed at birth, 3, 6 and 9 months: according to different maternal or newborn factors

\begin{tabular}{|c|c|c|c|c|}
\hline Factor & At hospital discharge & 3 months & 6 months & 9 months \\
\hline All participants & $79.2(76.4,81.7)$ & $56.6(53.2,59.8)$ & $42.9(39.6,46.1)$ & $32.2(29.2,35.3)$ \\
\hline \multicolumn{5}{|l|}{ Maternal educational level } \\
\hline Primary studies & $69.0(61.8,75.1)$ & $43.9(36.7,50.8)$ & $32.6(26.0,39.4)$ & $26.2(20.1,32.7)$ \\
\hline Secondary studies & $81.1(72.3,87.4)$ & $50.9(41.1,60.0)$ & $37.7(28.6,46.9)$ & $34.9(26.0,44.0)$ \\
\hline Foundation degree & $76.0(70.2,80.8)$ & $48.8(42.5,54.8)$ & $34.3(28.5,40.1)$ & $22.1(17.2,27.3)$ \\
\hline University studies & $86.9(82.7,90.2)$ & $71.3(66.1,76.0)$ & $57.3(51.7,62.5)$ & $43.0(37.5,48.3)$ \\
\hline \multicolumn{5}{|l|}{ Maternal occupation } \\
\hline Working & $79.2(75.7,82.2)$ & $59.2(55.2,63.0)$ & $43.4(39.5,47.3)$ & $31.5(27.8,35.2)$ \\
\hline Unemployed & $59.2(55.2,63.0)$ & $53.6(45.4,61.2)$ & $43.7(35.7,51.4)$ & $35.8(28.2,43.4)$ \\
\hline Inactive & $78.1(68.9,84.9)$ & $44.8(35.1,54.0)$ & $37.1(28.0,46.3)$ & $31.4(22.8,40.4)$ \\
\hline Student & 100 & $66.7(28.2,87.8)$ & $55.6(20.4,80.5)$ & $33.3(7.8,62.3)$ \\
\hline \multicolumn{5}{|l|}{ Smoking in pregnancy } \\
\hline No & $81.3(78.4,83.9)$ & $60.1(56.6,63.5)$ & $45.9(42.3,49.4)$ & $35.0(31.6,38.4)$ \\
\hline Yes & $65.2(55.8,73.1)$ & $33.0(24.6,41.7)$ & $22.6(15.5,30.6)$ & $13.9(8.3,20.9)$ \\
\hline \multicolumn{5}{|l|}{ Duration of pregnancy } \\
\hline$\geq 37$ weeks & $80.1(77.2,82.7)$ & $57.5(54.0,60.8)$ & $43.6(40.2,47.0)$ & $33.0(29.8,36.2)$ \\
\hline $34-36$ weeks & $65.8(48.5,78.5)$ & $50.0(33.4,64.5)$ & $34.2(19.8,49.1)$ & $26.3(13.7,40.8)$ \\
\hline$<34$ weeks & $68.4(42.8,84.4)$ & $31.6(12.9,52.3)$ & $26.3(9.6,46.8)$ & $10.5(1.8,28.4)$ \\
\hline \multicolumn{5}{|l|}{ Type of delivery } \\
\hline Vaginal (non-instumental) & $80.6(77.1,83.6)$ & $57.8(53.7,61.6)$ & $43.8(39.7,47.8)$ & $33.1(29.3,37.0)$ \\
\hline Instrumental & $80.0(69.0,87.4)$ & $58.7(46.7,68.8)$ & $40.0(28.9,50.8)$ & $26.7(17.3,37.0)$ \\
\hline Cesarean rate & $75.1(68.7,80.4)$ & $52.6(45.7,59.0)$ & $41.3(34.7,47.8)$ & $31.9(25.8,38.2)$ \\
\hline \multicolumn{5}{|l|}{ Newborn gender } \\
\hline Male & $79.0(74.9,82.6)$ & $58.8(54.0,63.2)$ & $44.9(40.2,49.5)$ & $34.4(30.0,38.9)$ \\
\hline Female & $79.4(75.3,82.9)$ & $54.4(49.6,58.9)$ & $40.8(36.2,45.4)$ & $30.1(25.8,34.4)$ \\
\hline \multicolumn{5}{|l|}{ Twin pregnancy } \\
\hline No & $79.9(77.0,82.5)$ & $57.3(53.9,60.6)$ & $43.7(40.3,47.0)$ & $33.0(29.9,36.2)$ \\
\hline Yes & $64.1(47.0,76.9)$ & $41.0(25.7,55.8)$ & $25.6(13.3,39.9)$ & $15.4(6.2,28.3)$ \\
\hline \multicolumn{5}{|l|}{ Newborn weight } \\
\hline$<2500$ & $67.5(56.1,76.6)$ & $36.3(25.9,46.7)$ & $31.3(21.5,41.5)$ & $18.8(11.1,28.0)$ \\
\hline $2500-4000 \mathrm{~g}$ & $80.4(77.3,83.1)$ & $58.5(54.9,62.0)$ & $43.7(40.1,47.3)$ & $33.0(29.6,36.4)$ \\
\hline$>4000 \mathrm{~g}$ & $80.6(68.9,88.2)$ & $59,7(47.0,70.3)$ & $47.8(35.5,59.1)$ & $40.3(28.6,51.7)$ \\
\hline
\end{tabular}

Note. Kaplan-Meier estimates and 95\% confidence intervals

To further clarify the impact each variable included in Table 3 multivariate model had on breastfeeding duration, Table 4 displays adjusted means and medians of breastfeeding duration. All means were higher than medians, indicating the distribution of breastfeeding duration is right skewed. Average duration of breastfeeding was 0.98 months longer for women aged 35 than for those aged 20; 2.24 months longer for women with university studies than for those with primary studies and 2.06 shorter for smokers than for non-smokers.

\section{Discussion}

In this cohort study, we have analysed how length of breastfeeding is conditioned by maternal characteristics (age, education, occupation activity, smoking habit), pregnancy features (duration, twin/single, type of delivery) and newborn attributes (gender, weight at birth). In a multivariate analysis that provides length of breastfeeding ratios, we found that breastfeeding was shorter in children born from mothers who were younger, without university studies or smoked in pregnancy, and those born from twin pregnancy or weighting less than $2500 \mathrm{~g}$ at birth.

The lack of quality information in previous studies prevented Cohen et al. from including maternal age in their meta-analysis on factors associated with breastfeeding initiation and continuation [13]. According to our results, each additional year in maternal age increases breastfeeding duration by $2 \%$ (i.e. time ratio $=1.02$ ); in this regard, if women aged 25 are expected to breastfed 


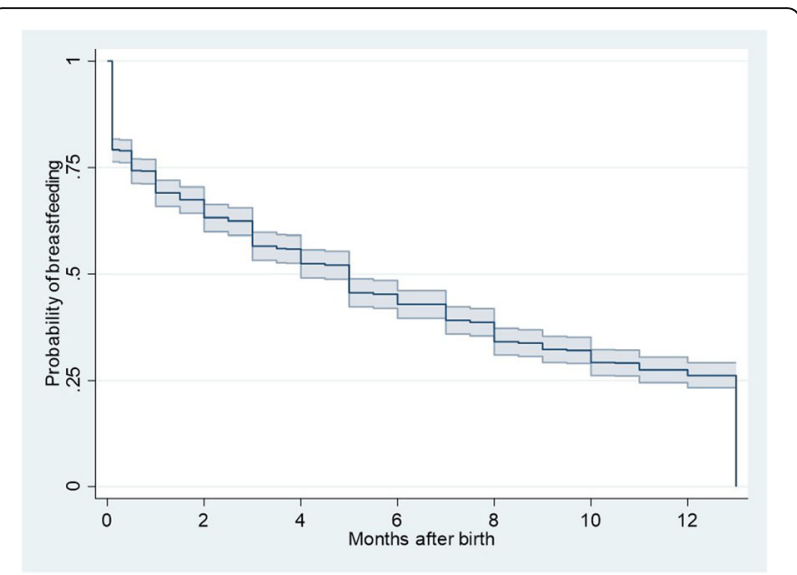

Fig. 2 Duration of breastfeeding in the whole cohort. Kaplan-Meier estimates with 95\% confidence bands

2.90 months on median, women 10 years older are expected to breastfed about $20 \%$ more time, until 3.50 months on median (Table 4). Scott et al. [15] found that 10 years more doubled the odds of breastfed continuation, although they did not study breastfeeding duration but its continuation until 4 months.

To study maternal education as factor associated with breastfeeding continuation is not straight forward as education attainment could be measured in different ways as educative systems are not always equivalent to each other. The easiest ways of making international results comparable are (i) measuring it in number of years of schooling [15], which assumes a linear effect (i.e. each additional educative year has the same effect on breastfeeding length) and (ii) restricting the analysis to a comparison between the highest and the lowest educational levels [13]. Both strategies mislay part of the information whether assuming a linear effect or omitting intermediate educational levels. We have found that, far from linear, the effect of maternal education in enlengthening breastfeeding only appears in mothers who have university studies and their children were breastfed for 53\% more time than those born from mothers with only primary studies. Of note, in the last decades, progressively higher proportions of Spanish women have attained university degrees, making it possible for $37 \%$ women in our cohort and even a higher percentage among those breastfeeding at hospital discharge (Table 1). Mechanisms for higher educated women to breastfeed longer are not clear. It has been suggested that they are more aware of the health implications of breastfeeding [16] and that they -being economically more independent than less educated women, and are empowered to make the decision on whether breastfeeding or not by themselves [17].
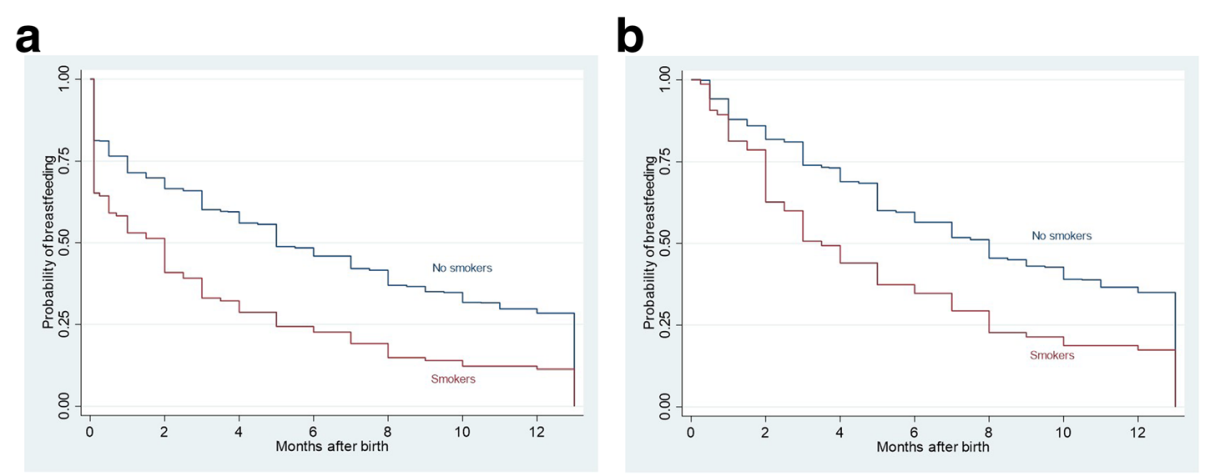

\section{C}
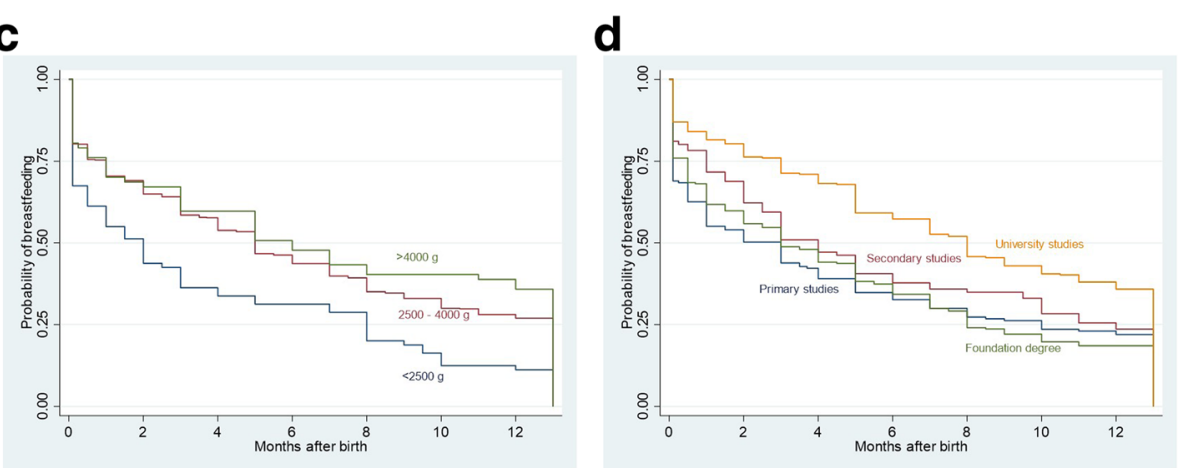

Fig. 3 Duration of breastfeeding according to (a) maternal smoking in the whole cohort, (b) maternal smoking only if children were breastfed at hospital discharge, (c) newborn weight and (d) maternal occupation 
Table 3 - Factors associated with breastfeeding duration: results obtained by Weibull regression

\begin{tabular}{|c|c|c|c|c|}
\hline Factor & $\begin{array}{l}\text { Time ratio } \\
(95 \% \mathrm{Cl})\end{array}$ & $p$ & Adjusted time ratio $(95 \% \mathrm{Cl})^{\mathrm{a}}$ & $p$ \\
\hline Maternal age (per year) & $1.03(1.01,1.04)$ & 0.002 & $1.02(1.00,1.04)$ & 0.03 \\
\hline \multicolumn{5}{|l|}{ Maternal educational level } \\
\hline Primary studies (ref.) & 1 & - & 1 & - \\
\hline Secondary studies & $1.26(0.93,1.70)$ & 0.14 & $1.28(0.95,1.74)$ & 0.11 \\
\hline Foundation degree & $1.05(0.83,1.34)$ & 0.68 & $0.99(0.77,1.26)$ & 0.92 \\
\hline University studies & $1.73(1.37,2.17)$ & $<0.001$ & $1.53(1.21,1.95)$ & $<0.001$ \\
\hline \multicolumn{5}{|l|}{ Maternal occupation } \\
\hline Working (ref.) & 1 & - & & \\
\hline Unemployed & $0.99(0.79,1.24)$ & 0.93 & & \\
\hline Inactive & $0.84(0.64,1.09)$ & 0.19 & & \\
\hline Student & $1.20(0.51,2.79)$ & 0.68 & & \\
\hline \multicolumn{5}{|l|}{ Smoking in pregnancy } \\
\hline No (ref.) & 1 & - & 1 & - \\
\hline Yes & $0.51(0.40,0.66)$ & $<0.001$ & $0.59(0.46,0.76)$ & $<0.001$ \\
\hline \multicolumn{5}{|l|}{ Duration of pregnancy } \\
\hline$\geq 37$ weeks (ref.) & 1 & - & 1 & - \\
\hline 34-36 weeks & $0.75(0.49,1.13)$ & 0.17 & $0.97(0.62,1.53)$ & 0.91 \\
\hline$<34$ weeks & $0.55(0.30,0.98)$ & 0.04 & $0.91(0.46,1.79)$ & 0.78 \\
\hline \multicolumn{5}{|l|}{ Type of delivery } \\
\hline Vaginal (non-instrumental)(ref.) & 1 & - & & \\
\hline Instrumental & $0.93(0.68-1.27)$ & 0.66 & & \\
\hline Cesarean rate & $0.93(0.76-1.13)$ & 0.46 & & \\
\hline \multicolumn{5}{|l|}{ Newborn gender } \\
\hline Male (ref.) & 1 & - & & \\
\hline Female & $0.92(0.78,1.10)$ & 0.37 & & \\
\hline \multicolumn{5}{|l|}{ Twin pregnancy } \\
\hline No (ref.) & 1 & - & 1 & - \\
\hline Yes & $0.56(0.37,0.85)$ & 0.006 & $0.57(0.37,0.89)$ & 0.01 \\
\hline \multicolumn{5}{|l|}{ Newborn weight } \\
\hline$<2500$ & $0.62(0.46,0.83)$ & 0.001 & $0.77(0.53,1.11)$ & 0.16 \\
\hline $2500-4000 \mathrm{~g}$ & 1 & - & 1 & - \\
\hline$>4000 \mathrm{~g}$ & $1.11(0.81,1.53)$ & 0.52 & $1.08(0.79,1.48)$ & 0.63 \\
\hline
\end{tabular}

${ }^{a}$ Time ratio adjusted for the remaining variables in the table. Occupation, type of delivery and gender were excluded from the multivariate analysis because of their lack of relationship with breastfeeding duration in the crude analysis

Note: that results are not express as hazard ratios but as time ratios. Therefore, values higher than 1 indicate longer breastfeeding, while values lower than 1 indicate the opposite. For instance, time ratio $=0.55$ in participants with pregnancy duration lower than 34 weeks means that breastfeeding duration in those participants about halved that of participants with pregnancy duration $>37$ weeks

Smoking in pregnancy has been largely and consistently identified as factor associated with both breastfeeding non-initiation and early discontinuation $[10,11,13]$. What our study adds is that breastfeeding lasted about $40 \%$ less in children born from mothers who smoked in pregnancy when compared with those from mothers who did not smoke. Among the identified factors influencing breastfeeding initiation and duration, smoking is probably the more modifiable and the more consistently associated with other deleterious effects on both mothers and children [18-20]. In spite of that, about 1 in 8 women in our cohort smoked in pregnancy, a similar percentage as reported in the US [13].

Shorter duration of pregnancy and lower weight at birth have been frequently found related to early breastfeeding discontinuation $[8,9,21]$. The fact that these two factors are strongly associated with each other makes it difficult to separate its effects. According to our 
Table 4 Breastfeeding duration in months

\begin{tabular}{|c|c|c|}
\hline Factor & Mean $(95 \% \mathrm{Cl})$ & Median $(95 \% \mathrm{Cl})$ \\
\hline \multicolumn{3}{|c|}{ Maternal age (selected ages) } \\
\hline 20 years & $5.05(4.09-6.00)$ & $2.63(1.97-3.29)$ \\
\hline 25 years & $5.37(4.72-6.03)$ & $2.90(2.38-3.41)$ \\
\hline 30 years & $5.70(5.29-6.11)$ & $3.18(2.80-3.56)$ \\
\hline 35 years & $6.03(5.69-6.36)$ & $3.50(3.15-3.85)$ \\
\hline \multicolumn{3}{|c|}{ Maternal educational level } \\
\hline Primary studies (ref.) & $5.03(4.30,5.77)$ & $2.78(2.22,3.33)$ \\
\hline Secondary studies & $5.82(4.87,6.76)$ & $3.57(2.67,4.46)$ \\
\hline Foundation degree & $4.95(4.34,5.56)$ & $2.74(2.29,3.20)$ \\
\hline University studies & $7.27(6.72,7.81)$ & $4.28(3.66,4.90)$ \\
\hline \multicolumn{3}{|l|}{ Smoking in pregnancy } \\
\hline No (ref.) & $6.21(5.86,6.56)$ & $3.62(3.25,3.99)$ \\
\hline Yes & $4.15(3.23,5.08)$ & $2.14(1.61,2.66)$ \\
\hline \multicolumn{3}{|l|}{ Duration of pregnancy } \\
\hline$\geq 37$ weeks (ref.) & $5.97(5.62,6.31)$ & $3.46(3.10,3.81)$ \\
\hline 34-36 weeks & $5.91(4.26,7.56)$ & $3.37(1.88,4.85)$ \\
\hline$<34$ weeks & $4.96(2.38,7.54)$ & $3.13(1.01,5.25)$ \\
\hline \multicolumn{3}{|l|}{ Twin pregnancy } \\
\hline No (ref.) & $6.02(5.69,6.36)$ & $3.51(3.15,3.87)$ \\
\hline Yes & $4.16(2.51,5.80)$ & $2.00(1.13,2.87)$ \\
\hline \multicolumn{3}{|l|}{ Newborn weight } \\
\hline$<2500 \mathrm{~g}$ & $5.01(3.71,6.30)$ & $2.68(1.74,3.63)$ \\
\hline $2500,4000 \mathrm{~g}$ & $6.00(5.63,6.36)$ & $3.49(3.11,3.86)$ \\
\hline$>4000 \mathrm{~g}$ & $6.49(5.30,7.67)$ & $3.77(2.61,4.92)$ \\
\hline
\end{tabular}

Note: Medians and means adjusted for the maternal age and the remaining variables in the table. Only variables in the multivariate analysis of Table 3 are included

results, the association between length of pregnancy and breastfeeding duration disappeared in the multivariate setting when adjusting for weight at birth, suggesting that lower weight at birth is the dominant factor of this finding.

The main point our study adds to literature is to present results as time ratios instead of the usual hazard ratios. Time ratios allows an easier interpretation, especially in the multivariate model where we can take advantage of its multiplicative nature. In this regard, we have shown an example on how a deleterious factor (smoking) could cancel out some positive factors (education level and maternal age), which reinforces the importance of acting on any preventable factor, whatever the exposure to the non-modifiable factors is.

Our study has some limitations. Firstly, length of breastfeeding was reported by mothers, so there is some room for information bias as some women could have informed according to social desires more than according to their actual practice. Secondly, although our sample size is close to 1000 mother-child dyads, some categories in the analysis have few participants, which makes some confidence intervals excessively wide; this could be the case of newborn weight lower than $2500 \mathrm{~g}$ or some categories in duration of pregnancy in the multivariate setting. Third, we have limited our research to variables standardly recorded in order to make our results more robust, but this strategy has left aside some important variables related to breastfeeding initiation and continuation, such as breastfeeding self-efficacy, return to work activity or previous breastfeeding experience. The main strength of our study is that women and children have been prospectively followed in a homogeneous way in a single centre committed to breastfeeding practices.

\section{Conclusion}

Using data from a prospective cohort study we have demonstrated the impact of several maternal and child factors on breastfeeding duration. The current trends to higher maternal age and increasing percentage of women with university studies would favour longer breastfeeding, on the other hand, a relatively high percentage of women smoking in pregnancy and a trend to increasing preterm births would counterbalance those benefits.

\section{Abbreviations \\ Cl: Confidence interval; HUMV: Hospital Universitario Marqués de Valdecilla; ICU: Intensive Care Unit; SD: Standard deviation}

\section{Authors' contributions}

Conceptualization, C.L.M., M.P.-Z., E.C.d.R., S.M.S., M.S.d.A., J.L. and M.J.C.P.; Data curation, C.L.M., E.C.d.R., S.M.S., M.S.d.A.; Formal analysis, C.L.M., M.P.-Z., J.L. and M.J.C.P.; Funding acquisition, C.L.M., M.P.-Z., E.C.d.R., S.M.S., M.S.d.A., and M.J.C.P.; Investigation, C.L.M., M.P.-Z., E.C.d.R., S.M.S., M.S.d.A., and M.J.C.P.; Methodology, C.L.M., M.P.-Z. and M.J.C.P.; Project administration, C.L.M., M.P.Z., E.C.d.R., S.M.S., M.S.d.A., and M.J.C.P.; Software, C.L.M., M.P.-Z., E.C.d.R., S.M.S., M.S.d.A. and M.M.P.; Supervision, M.P.-Z. J.L. and M.J.C.P.; Validation, C.L.M., M.P.-Z. J.L. and M.J.C.P.; Visualization, M.P.-Z. J.L. and M.J.C.P.; Writing—original draft, C.L.M., M.P.-Z., E.C.d.R., S.M.S., M.S.d.A., J.L. and M.J.C.P.; Writing-review \& editing, C.L.M., M.P.-Z. J.L. and M.J.C.P. All authors critically revised drafts of the work and approved the final version of the manuscript.

\section{Funding}

This research has been subsidized by the Valdecilla Health Research Institute (IDIVAL). Project awarded as the best project to be developed in Cantabria in the 19th call for research projects "Enfermería Valdecilla". The funders had no role in study design, data collection and analysis, decision to publish, or preparation of the manuscript.

\section{Availability of data and materials}

Data cannot be made publicly available in order to protect patient privacy. The data are available on request from the University of Cantabria Archive (http://repositorio.unican.es/) for researchers who meet the criteria for access to confidential data. Requests may be sent to the Ethics Committee (ceicc@idival.org) or Dr. María Paz-Zulueta (maria.paz@unican.es).

\section{Ethics approval and consent to participate}

This project was approved by the Ethics Committee for Clinical Research of Cantabria on July, 2017, reference number 2017.142. The parents signed an informed consent for participating in the study. The project was carried out according to the Spanish laws on biomedical research, the European Union 
regulations on the protection of natural persons with regard to the processing of personal data and the Declaration of Helsinki on ethical principles for medical research involving human subjects.

\section{Competing interests}

The authors declare no conflict of interest.

\section{Author details}

'Hospital Universitario Marqués de Valdecilla, 39008 Santander, Spain. ${ }^{2}$ Faculty of Nursing, Universidad de Cantabria. IDIVAL, GI Derecho Sanitario y Bioética. GRIDES, 39008 Santander, Spain. ${ }^{3}$ Universidad de Cantabria - IDIVAL, Santander, Spain. ${ }^{4}$ CIBER Epidemiology and Public Health (CIBERESP), Madrid, Spain.

Received: 23 April 2020 Accepted: 2 September 2020

Published online: 09 September 2020

\section{References}

1. World Health Organization. Global strategy for infant and young child feeding. Geneva; 2003. Available at: https://apps.who.int/iris/bitstream/ handle/10665/42590/9241562218.pdf;jsessionid=83B35EF2 E8FADC97887B7FAA407710AE? sequence=1. ISBN 9241562218

2. American Academy of Pediatrics. Breastfeeding and the use of human milk. Pediatrics. 2012;129:e827-41.

3. ESPGHAN Committee on Nutrition, Agostoni C, Braegger C, Decsi T, et al. Breast-feeding: a commentary by the ESPGHAN committee on nutrition. J Ped Gastroenterol Nut. 2009:49:112-25.

4. Theurich MA, Davanzo R, Busck-Rasmussen M, Díaz-Gómez NM, Brennan C, Kylberg E, et al. Breastfeeding rates and programs in Europe: a survey of 11 national breastfeeding committees and representatives. JPGN. 2019;68:4007.

5. Craighead DV, Elswick RK Jr. The influence of early-term birth on NICU admission, length of stay, and breastfeeding initiation and duration. JOGNN. 2014:43:409-21.

6. Busck-Rasmussen M, Villadsen SF, Norsker FN, Mortensen L, Andersen AM. Breastfeeding practices in relation to country of origin among women living in Denmark: a population-based study. Matern Child Health J. 2014;18: 2479-88.

7. Griffiths LJ, Tate AR, Dezateux C, The millennium cohort study child health group. The contribution of parental and community ethnicity to breastfeeding practices: evidence from the millennium cohort study. Int J Epidemiol. 2005:34:1378-86.

8. Apostolakis-Kyrus K, Valentine C, DeFranco E. Factors associated with breastfeeding initiation in adolescent mothers. J Pediatr. 2013;163:1489-94.

9. Häggkvist AP, Brantseter AL, Grjibovski AM, Helsing E, Meltzer HM, Haugen M. Prevalence of breast-feeding in the norwegian mother and child cohort study and health service-related correlates of cessation of full breastfeeding. Public Health Nutr. 2010;13(12):2076-86.

10. Leung GM, Ho LM, Lam TH. Maternal, paternal and environmental tobacco smoking and breastfeeding. Paediatr Perinal Epidemiol. 2002;16(13):236-45.

11. Lechosa-Muñiz C, Paz-Zulueta M, Del Río EC, Sota SM, Herrero MS, Pérez $\mathrm{MM}$, et al. Impact of maternal smoking on the onset of breastfeeding versus formula feeding: a cross-sectional study. Int J Environ Res Public Health. 2019;16(24):4888.

12. Bramson L, Lee JW, Moore E, Montgomery S, Neish C, Bahjri K, et al. Effect of early skin-to-skin mother-infant contact during the first 3 hours following birth on exclusive breastfeeding during the maternity hospital stay. J Hum Lact. 2010;26:130-7.

13. Cohen SS, Alexander DD, Krebs NF, Young BE, Cabana MD, Erdmann P, et al. Factors associated with breastfeeding initiation and continuation: A MetaAnalysis. J Pediatr. 2018;203:190-196.e21.

14. Carroll KJ. On the use and utility of the Weibull model in the analysis of survival data. Control Clin Trials. 2003;24:682-701.

15. Scott JA, Landers MCG, Hughes RM, Binns CW. Factors associated with breastfeeding at discharge and duration of breastfeeding. J Paediatr Child Health. 2001;37:254-61.

16. Cordova L, Dias de Oliveira LD, Justo ER. Factors associated with low incidence of exclusive breastfeeding for the first 6 months. Birth. 2007:34: 212-9.
17. Laughlin L. Maternity leave and employment patterns of first-time mothers 1961-2008. In: Current Population Report: US Department of Commerce; 2011. p. $70-113$.

18. Pineles BL, Hsu S, Park E, Samet JM. Systematic review and meta-analyses of perinatal death and maternal exposure to tobacco smoke during pregnancy. Am J Epidemiol. 2016;184:87-97.

19. Pereira PP, Da Mata FA, Figueiredo AC, de Andrade KR, Pereira MG. Maternal active smoking during pregnancy and low birth weight in the Americas: a systematic review and meta-analysis. Nicotine Tob Res. 2017;19:497-505.

20. Soneji S, Beltrán-Sánchez H. Association of maternal cigarette smoking and smoking cessation with preterm birth. JAMA Netw Open. 2019;2:e192514.

21. McDonald SD, Pullenayegum E, Chapman B, Vera C, Giglia L, Fusch C, et al. Prevalence and predictors of exclusive breastfeeding at hospital discharge. Obstet Gynecol. 2012;119:1171-9.

\section{Publisher's Note}

Springer Nature remains neutral with regard to jurisdictional claims in published maps and institutional affiliations.
Ready to submit your research? Choose BMC and benefit from:

- fast, convenient online submission

- thorough peer review by experienced researchers in your field

- rapid publication on acceptance

- support for research data, including large and complex data types

- gold Open Access which fosters wider collaboration and increased citations

- maximum visibility for your research: over $100 \mathrm{M}$ website views per year

At $\mathrm{BMC}$, research is always in progress.

Learn more biomedcentral.com/submissions 